\title{
THE STRATEGY OF JURNAL ADABIYAH IN PUBLISHING SCHOLARLY PAPERS
}

\author{
Asmiati Abdullah ${ }^{1}$ \& \& Gustia Tahir ${ }^{2}$ \\ ${ }^{1}$ Mahasiswa Jurusan Ilmu Perpustakaan, Universitas Islam Negeri Alauddin Makassar \\ ${ }^{2}$ Dosen di Jurusan Ilmu Perpustakaan, Universitas Islam Negeri Alauddin Makassar \\ Correspondence email: asmiatiabdullah7@gmail.com
}

\begin{abstract}
One of scientific publications in academic institutions is a scholarly journal. This study will describe the strategy of Jurnal Adabiyah in UIN Alauddin so that it can still exist until today in publishing scholarly papers and can be recognized as National accredited journal with Grade Sinta 2. The data were obtained through interviews with several journal editors, observations and documentation through the journal website. This research shows that in general outlines there are three strategies undertaken by Jurnal Adabiyah Journal to continue to exist which are maintaining teamwork, holding scientific activities, and promoting the journal. This research can be used as one of references for scientific publications, particularly for scientific journals in UIN Alauddin.
\end{abstract}

Keywords: Scholarly publication; journal publishing strategy

\begin{abstract}
Abstrak
Salah satu media publikasi ilmiah di perguruan tinggi ialah jurnal. Penelitian ini akan menggambarkan bagaimana strategi Jurnal Adabiyah UIN Alauddin Makassar yang hingga saat ini masih eksis menerbitkan artikel-artikel ilmiah dan dapat pengakuan terakreditasi Nasional peringkat Sinta 2. Data penelitian diperoleh melalui wawancara dengan beberapa editor jurnal, observasi dan dokumentasi langsung pada laman website jurnal. Penelitian ini menunjukkan bahwa secara garis besar ada tiga strategi yang dilakukan Jurnal Adabiyah hingga tetap eksis yakni menjaga kerja sama tim, mengadakan kegiatan-kegiatan ilmiah, dan gencar promosi. Penelitian ini dapat dijadikan salah satu rujukan bagi media-media terbitan ilmiah, khususnya jurnal-jurnal ilmiah yang ada di kampus UIN Alauddin Makassar.
\end{abstract}

Kata kunci: Publikasi ilmiah, strategi publikasi jurnal 


\section{Pendahuluan}

Publikasi ilmiah menjadi salah satu indikator sebuah perguruan tinggi (Nugrohoadhi, 2017). Ada beberapa bentuk publikasi ilmiah, di antaranya ialah yang diterbitkan dalam bentuk jurnal ilmiah yang saat ini hampir setiap perguruan tinggi di Indonesia telah memiliki dan mengembangkan jurnal ilmiahnya masingmasing sesuai dengan disiplin ilmunya. Apalagi menghasilkan sebuah publikasi ilmiah ialah suatu keharusan bagi setiap sivitas akademika.

UIN Alauddin Makassar saat ini telah memiliki puluhan jurnal ilmiah yang terdata pada website Rumah Jurnal UIN Alauddin Makassar (lihat http://journal.uinalauddin.ac.id/). Dari puluhan jurnal tersebut, di antaranya terdapat 36 yang telah terakreditasi Nasional, selebihnya masih dapat proses ke sana. Salah satu jurnal terakreditasi Nasional peringkat Sinta 2 diterbitkan Fakultas Adab dan Humaniora ialah Jurnal Adabiyah. Jurnal ini telah belasan tahun dimanfaatkan oleh sivitas kampus, baik untuk menerbitkan karya-karya tulis ilmiah maupun sebagai salah satu rujukan bahan bacaan di fakultas tersebut.

Mengelola informasi ilmiah, yang dalam kasus ini ialah penerbitan jurnal ilmiah bukanlah pekerjaan yang mudah. Pengelolaan jurnal ilmiah mesti mengikuti aturanaturan yang berlaku, seperti adanya etika publikasi, adanya dewan editor, mitra bestari, dan tentu saja penulis beserta dengan tulisan ilmiahnya. Tidak heran mengapa banyak perpustakaan perguruan tinggi membeli atau berlangganan jurnal karena informasi yang dikandung pada jurnal ilmiah ialah bersifat ilmiah.

Beberapa hasil penelitian menyatakan bahwa strategi publikasi jurnal sangat mempengaruhi baik tidaknya kandungan jurnal tersebut yang pada akhirnya dapat pengakuan dari komunitas pembaca. Dengan strategi tersebut lahirlah jurnal-jurnal Nasional hingga ke jurnal-jurnal yang bereputasi Internasional. Khulzannah (2018: 238) mengatakan strategi publikasi ilmiah yang merupakan salah satu perhatian khusus bagi perguruan tinggi, karena kualitas perguruan tinggi saat ini mulai diukur dari publikasi ilmiah yang telah diterbitkan. Sementara itu, Junandi (2018) mengatakan "minimnya jurnal terakreditasi sebagai media publikasi dan penyebaran informasi dari hasil penelitian. Sementara hasil kajian dari mahasiswa, dosen dan peneliti terus meningkat". Hal tersebut menunjukkan bahwa strategi itu sangat penting dalam kegiatan publikasi jurnal.

Jurnal Adabiyah sendiri hingga saat ini telah menerbitkan 19 Volume sebanyak 178 artikel sejak tahun 1997 hingga 2019. Untuk meraih pengakuan sebagai jurnal terakreditasi Nasional, tentu jurnal tersebut memiliki strateginya. Sebagaimana yang diketahui bahwa jurnal yang mendapat pengakuan Nasional ialah artinya jurnal bisa mendapat banyak perhatian dari kalangan pembaca maupun tulisan-tulisan yang berkualitas. Inilah yang mendasari penulis untuk lebih mendalami bagaimana strategi penerbitan di Jurnal Adabiyah yang hingga saat ini masih tetap eksis menberbitkan karya-karya tulis ilmiah yang dapat dimanfaatkan oleh banyak orang.

\section{Methods}

Penelitian deskriptif kualitatif hanya akan menggambarkan strategi-strategi penerbitan tanpa ingin lebih jauh menganalisisnya. Data diperolah melalui 
wawancara dengan sebagian besar editor jurnal, termasuk editor-in-chief Jurnal Adabiyah. Sumber lainnya diperolah melalu dokumentasi dari website Jurnal Adabiyah pada laman http://journal.uin-alauddin.ac.id/index.php/adabiyah. Hasil wawancara direduksi dan disajikan poin utamanya saja.

\section{Results}

Sebagaimana yang telah disampaikan sebelumnya bahwa hampir setiap perguruan tinggi di dunia ini membeli atau melanggan jurnal-jurnal ilmiah, baik Nasional maupun Internasional. Melihat ini, artinya ada bisnis dalam penerbitan publikasi ilmiah, seperti yang dilaporkan oleh Buranyi (2017) di laman The Guardian.

Strategi publikasi jurnal perlu dilakukan agar suatu kegiatan yang telah direncanakan tercapai sesuai tujuan yang telah ditentukan. Strategi merupakan salah satu cara atau langkah yang digunakan suatu lembaga atau organisasi untuk mencapai suatu perencanaan. Untuk Jurnal Adabiyah, ada 3 kegiatan utama yang menunjang proses publikasi yaitu sebagaimana yang tersaji pada gambar di bawah.

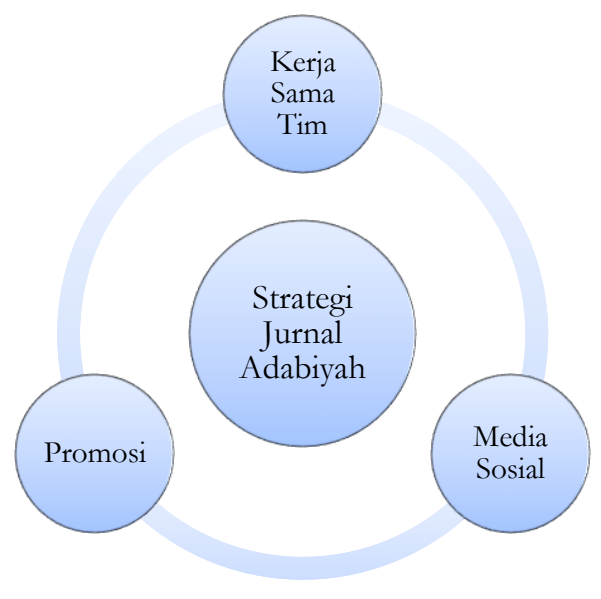

Gambar 1: Kegiatan Publikasi Jurnal Adabiyah

Pengertian sederhana organisasi ialah kelompok kerja sama antara orang-orang yang diadakan untuk mencapai tujuan bersama (KBBI online, 2012-2019). Jurnal Adabiyah memiliki tim editor dan kerjasama yang telah dibangun sejak dulu. Khusus untuk kerjasama, ini semakin intensif ketika hendak diajukan akreditasi. Jurnal ini membentuk tim profesional yang mengadakan pelatihan-pelatihan dosen yang nantinya dapat berkontribusi pada jurnal. Dalam dunia jurnal, tim ini diistilahkan dengan tim editor.

Dalam kegiatan publikasi ini, para editor bekerja sama dengan penulis dalam maupun penulis luar agar dapat menerbitkan tulisan-tulisan yang sesuai dengan standar Jurnal Adabiyah yang telah disebutkan pada laman 'author guidelines'. Kegiatan ini bertujuan untuk meningkatkan kualitas tulisan yang hendak dipublikasi. 
Dalam hal promosi, tim editor berbagi hal mengenai jurnal dengan memanfaatkan soaial media seperti facebook dan whatsapp (ketika penelitian ini dibuat, editor jurnal juga sedang menyiapkan beberapa video terkait jurnal yang hendak dimasukkan ke YouTube). Hal ini sangat mendukung kegiatan publikasi Jurnal Adabiyah. Satu di antaranya, masyarakat luas lebih cepat mengetahui terbitanterbitan terbaru yang telah dipublikasi oleh jurnal.

\section{Diskusi dan Kesimpulan}

Tiga strategi utama yang dilakukan Jurnal Adabiyah UIN Alauddin Makassar yaitu tim dan kerjasma, memanfaatkan sosial media, dan promosi. Ketiga strategi tersebut saling bersinergi satu sama lain. Strategi, sebagaimana yang dikemukakan oleh Pearce (2014:4) bahwa strategi adalah rencana skala besar yang berorientasi jangka panjang untuk berinteraksi dengan lingkungan yang kompetitif untuk mencapai tujuan suatu organisasi atau lembaga. Jurnal Adabiyah telah melakukan strategi dengan baik sesuai dengan perencanaan yang meliputi langkah-langkah dalam menjalankan kegiatan-kegiatan yang telah disepakati bersama untuk mencapai tujuan yang telah ditentukan, baik dalam jangka waktu pendek maupun dalam jangka waktu panjang.

Dengan adanya strategi tersebut, jurnal yang tiap Juni dan Desember menerbitkan artikel-artikel dengan tema Studi Islam dan Humaniora ini, kedepannya akan lebih meningkatkan kualitas artikelnya. Ini tentu baik, terkhusus masyarakat umum yang menggunakan jurnal ilmiah sebagai rujukan utamanya, seperti yang didefinisikan oleh Sutarno (2008). Singkatnya, jurnal ilmiah dapat memberikan pencerahan kepada masyarakat luas di tengah banyaknya informasi simpar siur saat ini.

\section{Acknowledgement}

Penulis mengucapkan terima kasih kepada seluruh dewan redaksi Jurnal Adabiyah atas perkenannya menerima kami untuk mengumpulkan data pada kajian ini.

\section{References}

Perpustakaan Nasional RI. "Undang-Undang Republik Indonesia Nomor 43 Tahun 2007”www.bpkp.go.id.

https://www.slideshare.net/M_AliAmiruddin/undang undang-no-43tahun-2007-tentang-perpustakaan (accessed 29 Oktober 2019).

Buranyi, S. (2017). Is the staggeringly profitable business of scientific publishing bad for science? https:/ /www.theguardian.com/science/2017/jun/27/profitable-businessscientific-publishing-bad-for-science (accessed 12 Desember 2019)

Junandi, S. "Pengelolaan Jurnal Elektronik Bidang Perpustakaan Menuju Jurnal Terakreditasi". Journal of Library and Information Science. https:/ / pustabiblia.iainsalatiga.ac.id/index.php/pustabiblia/article/viewFil e/1836/968 (accessed 29 Oktober 2019).

KBBI Online. (2012-2019). https://kbbi.web.id/organisasi 
Khulzannah, Miftah. "Strategi Peningkatan Publikasi Ilmiah di Universitas Gadjah Mada". Jurnal Ilmu Perpustakaan dan Informasi. http://jurnal.uinsu.ac.id/index.php/jipi/article/view/3239/1919 (accessed 29 Oktober 2019).

Nugrohoadhi, A. (2017). Pemanfaatan Publikasi Ilmiah di Perguruan Tinggi. Pustakaloka. 9(2).

Pearce, A. J. (2014). Manajemen Strategis: Formulasi, Implementasi, dan Pengendalian. Jakarta: Salemba Empat.

Sutarno NS. (2018). Kamus Perpustakaan dan Informasi. Jakarta: Jala 